\title{
AUDIT SISTEM INFORMASI PADA PT WALEPAY FINANSIAL TEKNOLOGI MENGGUNAKAN KERANGKA KERJA COBIT 4.1 DAN BALANCED SCORECARD
}

\section{AUDIT OF INFORMATION SYSTEMS IN PT WALEPAY FINANSIAL TEKNOLOGI USING COBIT 4.1 AND BALANCED SCORECARD}

\author{
Roby Wijaya $^{1}{ }^{*}$, Honni ${ }^{2)}$ Hendry Pratama ${ }^{3)}$ \\ 1) Program Studi Manajemen, Universitas Satya Negara Indonesia, Jakarta \\ 2,3) Program Studi Sistem Informasi, Universitas Bunda Mulia, Jakarta
}

Diterima 18 Februari 2020 / Disetujui 27 Februari 2020

\begin{abstract}
PT Walepay Financial Technology is a company in the field of financial technology (fintech). In this company the writer wants to know how well the implementation of governance has been run by PT Walepay Financial Technology. By using the COBIT 4.1 framework and BSC Model. The writer will measure the level of maturity in the application and planning section. The author uses 10 domains namely PO1, PO2, P03, PO4, PO5, PO6, PO7, PO8, PO9, and PO10. For the BSC model, the authors use the company's internal perspective. For the level of maturity obtained in the POI and PO6 domains with a value of 3 , while the lowest is in the PO7 domain with a value of 1.5. The recommendation for the PO domain is to finalize the IT implementation plan again in the company, especially in establishing the IT process relationship with the organization, maximizing the existing IT investment, and paying more attention to the risks inherent in the presence of IT. Based on the results obtained by the author, the authors provide advice to companies to take into account IT risks in the future so that future company planning is better. The authoralso uses the Balanced Scorecard to see perspectives from internal business processes and learning and growth perspectives. From the perspective of internal business processes, the company is good enough in running business processes, while from the perspective oflearning and growth, the company is also quite good. The average of the ten PO domains is 2.25, which is in the Repeatable but Intuitive stage Keywords: Financial Technology, COBIT 4.1, Maturity Level, Domain PO, Balanced Scorecard
\end{abstract}

\section{ABSTRAK}

PT Walepay Finansial Teknologi adalah sebuah perusahaan dibidang teknologi finansial (tekfin). Pada perusahaan ini penulis ingin mengetahui seberapa baik penerapan tata kelola yang sudah dijalankan oleh PT Walepay Finansial Teknologi. Dengan menggunakan kerangka kerja COBIT 4.1 dan BSC Model. Penulis akan mengukur tingkat kematangan pada bagian penerapan pengaturan dan perencanaannya. Penulis menggunakan 10 domain yaitu PO1, PO2, P03, PO4, PO5, PO6, PO7, PO8, PO9 dan PO10. Untuk BSC modelnya, penulis menggunakan perspektif internal perusahaan. Untuk tingkat kematangan didapat pada domain PO1 dan PO6 dengan nilai 3, sedangkan terendah terdapat pada domain PO7 dengan nilai 1,5. Rekomendasi untuk domain PO adalah mematangkan lagi rencana penerapan TI pada perusahaan, terutama dalam menetapkan hubungan pro ses TI dengan organisasi, memaksimalkan investasi TI yang ada, serta lebih memperhatikan lagi resiko resiko yang ada dari kehadiran TI. Berdasarkan hasil yang didapatkan penulis, penulis memberikan saran kepada perusahaan untuk memperhitungkan resiko TI pada masa mendatang agar perencanaan perusahaan kedepannya lebih baik. Penulis juga menggunakan Balanced Scorecard untuk melihat perspektif dari proses bisnis internal dan perspektif pembelajaran, dan pertumbuhan. Dari perspektif proses bisnis internal, perusahaan sudah cukup baik dalam menjalankan proses bisnis, sedangkan dari perspektif pembelajaran dan pertumbuhan, perusahaan juga sudah cukup baik. Rata-rata dari hasil kesepuluh domain PO adalah 2,25 yaitu dalam tahap Repeatable but Intuitive.

Kata Kunci: Teknologi Finansial, COBIT 4.1, Tingkat Kematangan, Domain PO, Balanced Scorecard

\footnotetext{
*Korespondensi Penulis :

E-mail: r088y.wijaya@gmail.com
} 


\section{PENDAHULUAN}

Pemenuhan kebutuhan akan sistem informasi bagi semua jenis organisasi menyebabkan perkembangan sistem informasi yang begitu pesat (Fitrianah dan Sucahyo 2008). Pada era informasi sekarang ini pemanfaatan teknologi informasi merupakan strategi yang sangat jitu untuk keunggulan bersaing (Pardiansyah, 2015). Sistem informasi adalah kombinasi teratur dari orang-orang, hardware, software, jaringan komunikasi dan sumber daya data yang mengumpulkan, mengubah, dan menyebarkan informasi dalam sebuah organisasi (Dewi, dkk, 2012). Teknologi informasi adalah seperangkat alat yang membantu Anda bekerja dengan informasi dan melakukan tugas-tugas yang berhubungan dengan pemrosesan informasi (Sihotang, 2015).

Kesuksesan tata kelola perusahaan (enterprise governance) saat ini mempunyai ketergantungan terhadap sejauh mana tata kelola TI (IT Governance) dilakukan. Keselarasan antara penerapan TI dengan strategi bisnis dan tujuan organisasi dapat dicapai melalui pengelolaan TI yang baik (Megawati dan Amrullah, 2014). Audit Teknologi informasi pada hakekatnya merupakan salah satu dari bentuk audit operasional, tetapi kini audit teknologi informasi sudah dikenal sebagai satu satuan jenis audit tersendiri yang tujuan utamanya lebih untuk meningkatkan tata kelola IT (Andry, 2016).

PT. Walepay Finansial Teknologi merupakan perusahaan perseroan terbatas yang baru berdiri pada awal Agustus 2018 yang bergerak pada bidang aplikasi finansial teknologi. PT. Walepay Finansial Teknologi juga menerapkan teknologi informasi untuk membantu mereka mencapai hasil yang diinginkan, untuk itu penulis ingin mengetahui seberapa matang persiapan tata kelola yang sudah dijalankan oleh PT. Walepay Finansial Teknologi menggunakan kerangka kerja dari COBIT 4.1 yang berfokus pada domain Plan and Organize.

COBIT merupakan suatu kerangka kerja atau panduan standar praktik manajemen teknologi informasi. Praktikpraktik tersebut akan membantu mengoptimalkan investasi teknologi informasi, memastikan penyampaian layanan dan menghasilkan pengukuran dalam menentukan saat dimana terjadi kesalahan (Arumana, 2014). COBIT telah terbukti sebagai kerangka kerja yang baik untuk melakukan audit tata kelola. Terdapat 4 domain utama yaitu: Pland and Organize(PO), Acquire and Implement(AI), Deliver and Suppor(DS), Monitor and Evaluate(ME) (Andry, dan Hartono, 2017). Serta memiliki 34 proses yang merangkum 210 detailed control objective sesuai dengan bidang tanggung jawab, mulai dari perencanaan, membangun, menjalankan dan memonitor implementasi teknologi informasi, dan juga memberikan pandangan end-to-end teknologi informasi (Pribadi, 2015).

Untuk dapat memberi penilaian dari hasil audit tersebut, maka diukur dengan model kematangan (Maturity level). Model kematangan (maturity model) digunakan sebagai alat untuk melakukan benchmarking dan self-assessment oleh manajemen teknologi informasi secara lebih efisien (Supradono, 2011). Model kematangan terdiri dari lima tingkat kematangan pengelolaan IT, meliputi : tingkat 0 (non-existent), tingkat 1 (initial), tingkat 2 (repeatable), tingkat 3 (defined), tingkat 4 (managed), dan tingkat 5 (optimised). Semakin tinggi tingkat kematangan, akan semakin baik proses pengelolaan teknologi informasi (Suryani, 2009). 
Dalam penelitian pada PT. Walepay

Finansial Teknologi, penulis memfokuskan pada domain Plan and Organize. Metode penelitian menggunakan teknik pengumpulan data yaitu kuisioner, wawancara dan analisis data menggunakan kerangka kerja COBIT 4.1.

\section{METODE PENELITIAN}

Tahapan penelitian digambarkan pada gambar 1. Metode Penelitian

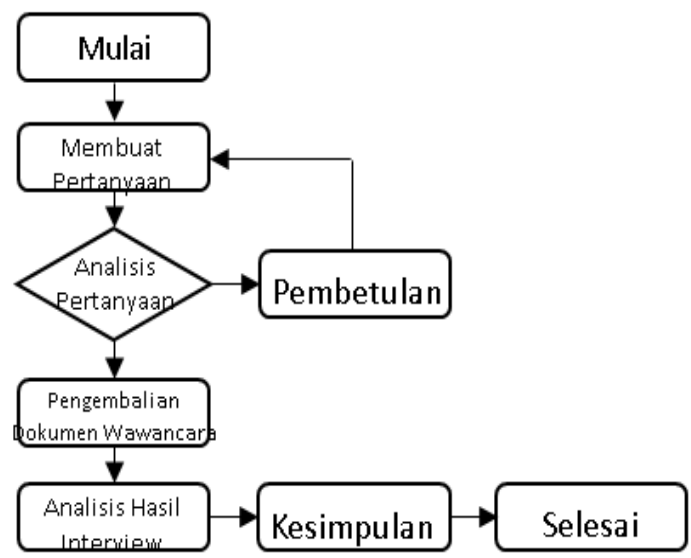

\section{Gambar 1. Metode Penelitian}

Hal pertama dalam melakukan penelitian adalah mengetahui dan mengerti masalah-masalah yang ada didalam perusahaan. Saat memulai melakukan penelitian, ada beberapa tahapan yang dilewati, yaitu: (1) Membuat pertanyaan untuk wawancara, (2) Menganalisis ulang pertanyaan yang akan diajukan, (3) Pembetulan akan dilakukan jika dirasa ada yang kurang, (4) Melakukan pengembalian dokumen wawancara, (5) Melakukan pengembalian dokumen wawancara, (6) Melakukan analisis hasil interview dengan narasumber, (7) Menyimpulkan dari hasilhasil yang didapat dari hasil wawancara. Untuk lebih jelasnya dapat dilihat pada Gambar 1. Metode Penelitian

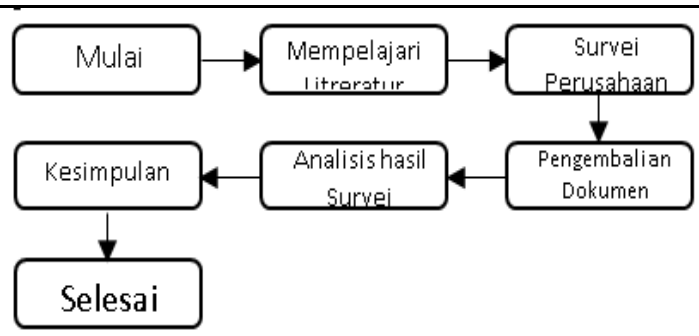

Gambar 2. Alur Proses Wawancara

Wawancara dilakukan kepada pihak perusahaan yang menjadi narasumber utama dalam penelitian ini adalah manajer dan staff, terutama manajer TI. Ada 5 alur proses wawancara, mulai dari mempelajari literatur, survei perusahaan, pengembalian dokumen, menganalisis hasil dari survei yang dilakukan, lalu membuat kesimpulannya, untuk melihat tahapannya dapat dilihat pada Gambar 2. Alur Proses Wawancara.

Semua pertanyaan yang dibuat dan ditanyakan bepedoman dari kerangka kerja COBIT 4.1 pada domain Plan and Organize, lalu dilanjutkan dengan survei mengunjungi perusahaan PT. Walepay Finansial Teknologi untuk melihat langsung kondisi nyata dari perusahaan, setelah dokumen dikira lengkap, maka akan dilanjutkan dengan menganalisis hasil dokumen yang telah diperoleh, dan membuat laporan tentang kesimpulan serta Balanced Scorecard dari data-data yang diperoleh.

\section{HASIL DAN PEMBAHASAN}

Berdasarkan hasil yang diperoleh dari wawancara dan kunjungan observasi lapangan ke PT Walepay Finansial Teknologi, penulis dapat mengukur tingkat kematangannya dengan menyesuaikan dengan kerangka kerja COBIT 4.1. Penulis melakukan wawancara kepada minimal 2 orang yang berbeda yang terkait dengan informasi yang dibutuhkan. Penulis akan membahas sub domain PO, meliputi PO1 (Menetapkan rencana strategis TI), PO3 
(Menetapkan arah teknologi), PO4 (Menetapkan proses TI, organisasi dan hubungannya), PO5 (Mengatur investasi TI), PO6 (Mengkomunikasikan tujuan dan arahan manajemen), dan PO9 (Menilai dan mengatur resiko TI).

\section{A. Domain PO}

Pada domain ini meliputi proses perencanaan dan menyelaraskan strategi TI dengan strategi perusahaan (sebagai organisasi), memetakan rencana perusahaan di bidang TI dimasa depan, merancang TI agar bekerja dengan baik dan lancar di dalam perusahaan. Penulis menggunakan domain PO1 sebab penulis ingin mengetahui seberapa matang penetapan rencana strategis di bidang TI dalam jangka pendek, maupun jangka panjang pada perusahaan. Domain PO2 digunakan penulis untuk menetapkan arsitektur sistem informasi yang diterapkan oleh perusahaan. Domain PO3 digunakan penulis untuk menilai penetapan arah teknologi di masa mendatang pada perusahaan. PO4 untuk mengetahui hubungan antara perusahaan dengan proses TI yang dijalankan. PO5 untuk mengetahui perencanaan investasi di bidang TI di waktu mendatang. PO6 untuk menilai koordinasi antara keinginan manajemen terhadap perangkat TI. PO7 digunakan untuk mengelola sumber daya manusia dengan menggunakan sistem informasi. PO8 digunakan untuk mengatur dan menjaga kualitas kinerja dari para karyawan dan juga layanan kepada pengguna aplikasi. PO9 untuk menilai dan mempertimbangkan resiko yang dihasilkan oleh adanya TI. Dan terakhir adalah PO10 untuk dalam rata-rata domain PO berapa nilainya dari semua yang sudah perusahaan lakukan.

Tabel 1. Tingkat kematangan PO

\begin{tabular}{|c|c|c|c|}
\hline Proses & \multicolumn{2}{|c|}{ Proses Objektif } & $\begin{array}{c}\text { Nilai } \\
\text { Kematangan }\end{array}$ \\
\hline PO1 & Menetapkan & rencana & 3 \\
\hline
\end{tabular}

\begin{tabular}{|c|c|c|}
\hline & strategis $\mathrm{TI}$ & \\
\hline $\mathrm{PO} 2$ & Menetapkan arsitektur SI & 2,5 \\
\hline $\mathrm{PO} 3$ & $\begin{array}{l}\text { Menetapkan arah } \\
\text { teknologi }\end{array}$ & 2,5 \\
\hline $\mathrm{PO} 4$ & $\begin{array}{llr}\begin{array}{l}\text { Menetapkan proses } \\
\text { organisasi }\end{array} & & \text { TI, } \\
\text { hubungannya } & & \\
\end{array}$ & 2 \\
\hline $\mathrm{PO5}$ & Mengatur investasi TI & 2 \\
\hline PO6 & $\begin{array}{l}\text { Mengkomunikasikan } \\
\text { tujuan dan arahan } \\
\text { manajemen }\end{array}$ & 3 \\
\hline $\mathrm{PO} 7$ & $\begin{array}{l}\begin{array}{l}\text { Mengelola sumber daya } \\
\text { manusia }\end{array} \\
\end{array}$ & 1,5 \\
\hline $\mathrm{PO} 8$ & Mengatur kualitas & 2 \\
\hline PO9 & $\begin{array}{l}\text { Menilai dan mengatur } \\
\text { resiko TI }\end{array}$ & 2 \\
\hline PO10 & $\begin{array}{l}\text { Mengatur proyek rata-rata } \\
\text { domain PO }\end{array}$ & 2 \\
\hline & Tingkat kematangan rata-rata & 2,25 \\
\hline
\end{tabular}

Dilihat dari Tabel 1. Tingkat Kematangan PO, berikut penulis memberikan penjelasan dari hasil tersebut:

\section{Sub-Domain PO1}

Dari hasil wawancara yang dilakukan, penulis memberikan nilai 3 atau Defined Process karena menilai bahwa PT Walepay Finansial Teknologi sudah cukup baik dalam menerapkan, membuat rencana strategis TI pada masa mendatang dikarenakan semua pencatatan rencana tertulis dan terjadwal dengan rapih.

\section{Sub-Domain PO2}

Dari hasil wawancara, penulis memberikan nilai 2,5 atau Repeatable but Intuitive karena mengetahui bahwa dalam penerapan arsitektur di PT Walepay Finansial Teknologi lumayan baik. Perusahaan sudah memetakan atau merencanakan kebutuhankebutuhan informasi apa saja yang dibutuhkan dimasa sekarang dan dimasa depan.

\section{Sub-Domain PO3}

Dari hasil wawancara, penulis memberikan nilai 2,5 atau Repeatable but Intuitive karena PT Walepay Finansial 
Teknologi sudah cukup baik dalam menggambarkan arah tujuan dari arah teknologinya. Perusahaan mempunyai rencana ke arah yang futuristik, namun masih belum dapat digambarkan dengan jelas.

\section{Sub-Domain PO4}

Dari hasil wawancara, penulis memberikan nilai 2 atau Repeatable but Intuitive karena hubungan dari proses TI dan organisasi/perusahaan masih belum begitu berjalan dengan baik, masih ada kesalahpahaman dari kedua hubungan tersebut.

\section{Sub-Domain PO5}

Dari hasil wawancara, penulis memberikan nilai 2 atau Repeatable but Intuitive karena investasi yang dilakukan oleh PT Walepay Finansial Teknologi belum maksimal, namun untuk saat ini investasi TI yang dilakukan perusahaan sudah memenuhi kebutuhannya.

\section{Sub-Domain PO6}

Dari hasil proses wawancara, penulis memberikan nilai 3 atau Defined Process karena penulis menilai antara tujuan keinginan dari pihak manajemen perusahaan dapat dikomunikasikan dengan baik kepada divisi TI dan dikerjakan dengan baik, serta memberikan masukan-masukan atau solusi jika dirasa keinginan yang diharapkan pihak manajemen tidak bagus untuk keberlangsungan sistem informasi.

\section{Sub-Domain PO7}

Dari hasil proses wawancara, penulis memberikan nilai 1,5 atau Initia/Ad Hoc karena menurut penilaian penulis, PT Walepay Finansial Teknologi mempunyai karyawan yang masih sedikit, dan untuk sistem informasinya masih baru saja diterapkan, namun perusahaan menyadari bahwa pentingnya membuat perencanaan untuk mengelola sumber daya manusia.

\section{Sub-Domain PO8}

Dari hasil wawancara, penulis memberikan nilai 2 atau Repeatable but Intuitive karena penulis menilai bahwa perusahaan dalam masa proses penerapaan yang berulang dalam mengatur kualitasnya.

\section{Sub-Domain PO9}

Dari hasil wawancara dengan penulis, penulis memberikan nilai 2 atau Repeatable but Intuitive karena penulis menilai bahwa PT Walepay Finansial Teknologi sudah melakukan proses menilai resiko-resiko TI yang ada dan yang akan datang, dan mulai melakukan antisipasi terhadap resiko IT tersebut.

\section{Sub-Domain PO10}

Dari hasil wawancara, penulis memberikan nilai 2 atau Repeatable but Intuitive karena dari semua domain PO yang dijalankan oleh perusahaan, PT Walepay Finansial Teknologi rata-rata masih dalam proses perencanaan meskipun ada beberapa yang sudah Defined Process.

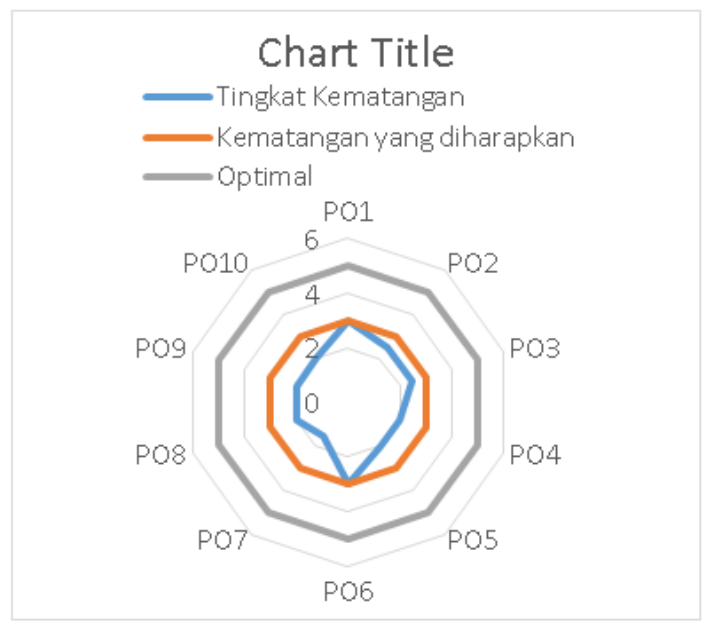

Gambar 3. Grafik Tingkat Kematangan 
Berikut diatas penulis sajikan grafik dari tingkat kematangan sepuluh domain Plan and Organize dari PT Walepay Finansial Teknologi dapat dilihat pada Gambar 3. Grafik Tingkat Kematangan.

\section{B. Rekomendasi Untuk Domain PO}

Dari penulis memberikan rekomendasi untuk domain PO ini adalah mematangkan lagi rencana penerapan TI pada perusahaan, terutama dalam menetapkan hubungan proses TI dengan organisasi, memaksimalkan investasi TI yang ada, serta lebih memperhatikan lagi resiko resiko yang ada dari kehadiran TI.

\section{Penyelarasan COBIT dan Balanced Scorecard}

Balanced Scorecard mengkonversi dari misi dan strategi menjadi sebuah indikator tolak ukur kinerja yang dapat dipahami, dan diukur. Pada Balanced Scorecard terdapat pengelompokan proses TI berdasarkan tujuan bisnis yang mengacu pada perspektif BSC.

Untuk perspektif proses bisnis internal, terdapat tiga hal yang digunakan untuk menganalisis tingkat keberhasilan PT Walepay Finansial Teknologi adalah sebagai berikut:

\section{Proses Inovasi}

Dari hasil wawancara dengan manajer TI sebagai divisi yang bertugas dalam mengembangkan aplikasi, PT Walepay Finansial Teknologi telah merampungkan beberapa fitur utama mereka dalam pembuatan aplikasi, dan untuk pengembangan fitur inovasi terbaru akan dilakukan menyesuaikan arahan tingkat manajerial tertinggi, namun biasanya akan dievaluasi setiap 2 bulan sekali dalam mengkaji inovasi dari fitur-fitur terbaru.

\section{Proses Operasi}

Berdasarkan dari hasil wawancara, penulis mengetahui bahwa proses kegiatan opersional dari PT Walepay Finansial Teknologi belum berjalan begitu baik dikarenakan masih belum banyaknya staff-staff yang bertugas secara khusus menangani suatu pekerjaan

3. Layanan Purna Jual

Berdasarkan dari hasil wawancara dan mencoba langsung dalam melakukan proses penjualan kepada pengguna terhitung cukup baik dan cepat, sehingga dalam melakukan transaksi seperti pembelian pulsa, listrik, air, dan bpjs dapat dilakukan dengan mudah dan cepat.

Untuk perspektif pembelajaran dan pertumbuhan ada tiga indikator dalam menilai kinerja dari PT Walepay Finansial Teknologi yaitu:

1. Kapabilitas Karyawan

Berdasarkan hasil wawancara, PT Walepay Finansial Teknologi memiliki sumber daya manusia yang cukup baik dalam menguasai peran dalam pekerjaannya. Selain itu, respon karyawan dalam menangani permasalahan yang ada juga sudah cukup baik

\section{Kapabilitas Sistem Informasi}

Berdasarkan pengamatan dan wawancara dengan manajer TI, PT Walepay Finansial Teknologi memiliki staff TI untuk mengolah data perusahaan. Staff TI juga membuat sistem informasi untuk menunjang para staff-staff lainnya dalam proses kegiatan bekerja.

3. Motivasi, Pemberdayaan, dan Keselarasan Dalam proses pemberdayaan staff di PT Walepay Finansial Teknologi, maka diadakan pelatihan bagi seluruh staffnya minimal 2 kali dalam setahun. Selain itu perusahaan juga berupaya meningkatkan kompetensi dari para staff dengan cara memberikan latihan pengembangan. 
Versi Online: http://journal.ubm.ac.id/index.php/jbase

DOI: http://dx.doi.org/10.30813/ibase.v3i1.2058

Hasil Penelitian
Journal of Businessand Audit Information Systems

Vol 3(No.1) : 14-21. 2020

p-ISSN: 2615-6431
Motivasi para staff juga diperlukan demi menjaga kinerja dari para staff dalam melakukan pekerjaan, maka dari itu minimal 2 kali dalam setaun diadakan seminar yang membangun yang ditujukan untuk para staff di PT Walepay Finansial Teknologi.

\section{KESIMPULAN DAN SARAN}

\section{A. Kesimpulan}

Kesimpulan dari hasil penelitian adalah subdomain PO1 dan PO6 adalah domain dengan tingkat nilai kematangan tertinggi, dimana nilai 3 adalah nilai kematangan yang diharapkan. Sedangkan nilai terendah adalah 1,5 pada domain PO7. Rata-rata dari hasil kesepuluh domain PO adalah 2,25 yaitu dalam tahap Repeatable but Intuitive yaitu tahap yang telah memiliki pola untuk mengelola proses tersebut berdasarkan pengalaman yang berulang pada waktu sebelumnya, namun belum terstandarisasi. Untuk Balanced Scorecard penulis menarik kesimpulan bahwa perspektif dari proses bisnis internal sudah cukup baik, dan juga dari perspektif pembelajaran dan pertumbuhan juga sudah cukup baik.

\section{B. Saran}

Saran dari penulis adalah melakukan pengoptimalan investasi IT untuk kepentingan yang mendesak dan sangat diperlukan terlebih dahulu. Selain itu juga PT Walepay Finansial Teknologi juga disarankan untuk menyelaraskan hubungan antara proses TI dengan organisasi perusahaan, serta memperhitungkan resiko TI pada masa mendatang agar perencanaan perusahaan kedepannya lebih baik.

\section{DAFTAR PUSTAKA}

Andry, J., F. 2016. Audit Sistem Informasi Sumber Daya Manusia Pada Training Center Di Jakarta Menggunakan
Framework COBIT 4.1. Jurnal Ilmiah FIFO. Vol. 8. No. 1.

Andry, J., F. dan Hartono, H. 2017. Performance Measurement of IT Based on COBIT Assessment: A Case Study. Jurnal Sistem Informasi Indonesia (JSII). Vol. 2. No. 1.

Andry, J., F. and Sebastian, B. 2018. Conceptual Framework For Successful IT-Governance and BSC for Service Industry. International Journal of Innovative Science and Research Technology. Vol. 3. No. 5.

Arumana, A. Rochim, A., F. dan Windasari, I., P. 2014. Analisis Tata Kelola Teknologi Informasi Menggunakan Kerangka Kerja COBIT 4.1 Pada Fakultas Teknik UNDIP. Jurnal Teknologi dan Sistem Komputer. Vol. 2. No. 2

Dewi, E., R. Tanuwijaya, H. dan Mastan, I., A. 2012. Audit Sistem Informasi Manajemen Aset Berdasarkan Perspektif Proses Bisnis Internal Balanced Scorecard Dan Standar COBIT 4.1. Jurnal JSIKA. Vol. 1. No. 2.

Fitrianah, D., dan Sucahyo, Y., G. 2008. Audit Sistem Informasi/Teknologi Informasi Dengan Kerangka Kerja COBIT untuk Evaluasi Manajemen Teknologi Informasi di Universitas XYZ. Jurnal Sistem Informasi MTI-UI. Vol. 4. No. 1.

Megawati, dan Amrullah, F. 2014. Evaluasi Tingkat Kematangan Teknolgi Inormasi Dengan Dengan Menggunakan Model Maturity Level COBIT 4.1 (Studi Kasus PT BRI Cabang Bangkinang). Jurnal Sains Teknologi dan Industri. Vol. 12. No. 1.

Pribadi, M., R. 2015. Penerapan Tata Kelola Teknologi Informasi Dengan Menggunakan COBIT Framework 4.1

(Studi Kasus Pada RSUD Bari Palembang). Eksplora Informatika. Vol. 4. No. 2.

Pardiansyah, A., S. 2015. Audit Tata Kelola Teknologi Informasi Program Studi 
Versi Online: http://journal.ubm.ac.id/index.php/jbase DOI: http://dx.doi.org/10.30813/jbase.v3i1.2058

Ha sil Penelitian
Journal of Businessand Audit Information Systems

Vol 3(No.1) : 14-21. 2020

p-ISSN: 2615-6431

e-ISSN: 2620-7907

$\begin{array}{lcr}\begin{array}{l}\text { Sistem Informasi sekolah } \\ \text { Manajemen }\end{array} \text { Tinggi } \\ \text { Komputer } & \text { (STMIK) } & \begin{array}{r}\text { Dombok } \\ \text { Deman }\end{array} \\ \begin{array}{l}\text { Menggunakan } \\ \text { Indonesian Joumework }\end{array} & \text { COBIT. } \\ \text { Engineering. Vol. 1. No. 1. } & & \text { Software }\end{array}$

Sihotang, H., T. 2015. Penerapan Tata Kelola Teknologi Informasi Dengan Menggunakan COBIT Framework 4.1 Studi Kasus Pada PT Perkebunan Nusantara III Medan (Persero). Jurnal Mantik Penusa. Vol. 17. No. 1.

Supradono, B. 2011. Tingkat Kematangan Tata Kelola Teknologi Informasi (IT Governance) Pada Layanan Dan Dukungan Teknologi Informasi (Kasus: Perguruan Tinggi Swasta Di Kota Semarang). Seminar Nasional Teknologi Informasi \& Komunikasi Terapan.

Suryani, A., A. 2009. Pengembangan Model Information Technology (IT) Governance Pada Organisasi Pendidikan Tinggi Menggunakan COBIT 4.1 Domain PO dan AI. Seminar Nasional Informatika.

(Studi Pengguna i - Tunes, Joox, Melon dan Spotify), $E-$ Proceeding of Management, vol 4, hal 2511-2518.

Luck, G, 2016, The Psychology of Streaming: Exploring Music Listeners' Motivations to Favour Access Over Ownership, International Journal of Music Business Research.

Pangastuti, D, 2015, Pengaruh Musik Dangdut Terhadap Perkembangan Bahasa Anak Di TK Dharma Wanita Madiun 2014/2015, Seminar Nasional Pendidikan UNS \& ISPI Jawa Tengah.

Pibriana, D, Ricoida, I, D, 2017, Analisis Pengaruh Penggunaan Internet Terhadap Minat Belajar Mahasiswa, JATISI.

Purnomo, A, Hartono, R, Hartatik, Riasti, K, B, Hidayah, N, I, 2016, Pengembangan Aplikasi Info Lagu Nusantara Berbasis
Android Untuk Melestarikan Warisan Budaya Indonesia, Jurnal SIMETRIS.

Sonang, S, 2013, Perencanaan dan Pembuatan Aplikasi Pemutaran MP3 Dengan Menggunakan Bahasa Delphi, Jurnal Murni Sadar.

Sutangi H, 2014, Hubungan Pengetahuan Dan Sikap Ibu Dengan Kejadian Pneumonia Balita Di Desa Telukagung Wilayah Kerja Uptd Puskesmas Plumbon Kecamatan Indramayu Kabupaten Indramayu Tahun 2014, Jurnal Kesehatan Masyarakat (AFIASI). 